\title{
Analyses of the Effect of Clamping Distance on Stress and Roll Stiffness of Anti Roll Bar
}

\author{
Aniket Kundlik Yachkal, Dr. Niloy K. Nath, Dr. Subim Khan \\ ${ }^{1}$ ME ( Design-Mechanical), Department of Mechanical Engineering, SPPU, Pune, Maharashtra, India. \\ ${ }^{2}$ Professor, Department of Mechanical Engineering, SPPU, Pune, Maharashtra, India. \\ ${ }^{3}$ Associate Professor, Department of Mechanical Engineering, SPPU, Pune, Maharashtra, India.
}

\begin{abstract}
The main objective of this paper is to find out what is the effect of change in Anti roll bar's roll stiffness and the stress developed, if clamping distance of Anti Roll bar is changed. The analysis have been done by using CATIA V5 software application for Generative Structure Analysis. This analysis is done on the basis of constant displacement, but in opposite direction, since the main motive of Anti roll bar is achieved by twisting it. Clamping distance of Anti roll bar is based on its chassis parameter. Recently offset link are used to achieve required clamping distance.
\end{abstract}

Keywords: Roll stiffness, twisting, constant displacement, Anti Roll Bar.

\section{INTRODUCTION}

Anti Roll Bar also known as stabilizer bar is part of suspension which helps to stabilize the vehicle for handling purpose. Anti roll bar are laterally assembled torsional spring which resist vertical displacement of tyres relative to one another. Vertical Suspension rate is not increased when both tyres are deflected simultaneously, but stiffness is increased for one tyre bump. Anti roll bar is generally installed in both front and rear suspension or in front suspension only. Use of Anti roll bar on the rear suspension only can have an adverse effect on vehicle handing. Such installation should be tested under serve cornering condition to ensure the desired handling characteristics have been meet.

Anti roll bar is one single piece $U$ shape bar (minuet geometry may change due to packing concern) which is fixed or clamped at one end and have constrained movement on other end. Constrained movement makes the principle of stabilization in action. Anti roll bar requires rubber or steel bush, Linkage and joinery arrangement with chassis and axle for functioning. As our objective is to design Anti Roll Bar and study the effect of clamping distance on roll stiffness and stress induced in it. Earlier ${ }^{[1]}$ Mohammad Durali and Ali Reza Kassaiezadeh studied and proposed the main aim of using anti-roll bar is to minimize the body roll. ${ }^{[2] ~ M r . ~ P r a v i n ~}$ Bharane, Mr. Kshitijit Tanpure and Mr. Ganesh Kerkal used Ansys Parametric Design language to calculate rolling stiffness, mass, deflection, Von-mises stresses. ${ }^{[3]} \mathrm{J}$. E. Shigley, C.R. Mischke explained that the moment makes the inner suspension to expand and the outer suspension to compress, thus the body roll takes place. ${ }^{[4]}$ D.J Bickerstaff discussed about the role of Anti roll bar in handling of truck. ${ }^{[6]}$ ZhongXing Li1, Rong-Zhou Xu explained roll stiffness optimization strategy of anti-roll bar in IAS based on genetic algorithm is done for better roll stiffness as well as better roll angle vibration characteristics. [7] $\mathrm{N}$. Zulkarnain presented a comparison of ride and handling analysis for an active antiroll bar system using various types of controller.

\section{PROBLEM DEFINITION}

To analyse the effect of clamping distance of Anti roll Bar over its rolling stiffness and stress induced in it, we are considering the same design for all the cases. The scenario of Anti roll bar twisting is kept same as $100 \mathrm{~mm}$ deflection at its eye end as the Anti roll bar came into action while cornering and one bump condition.

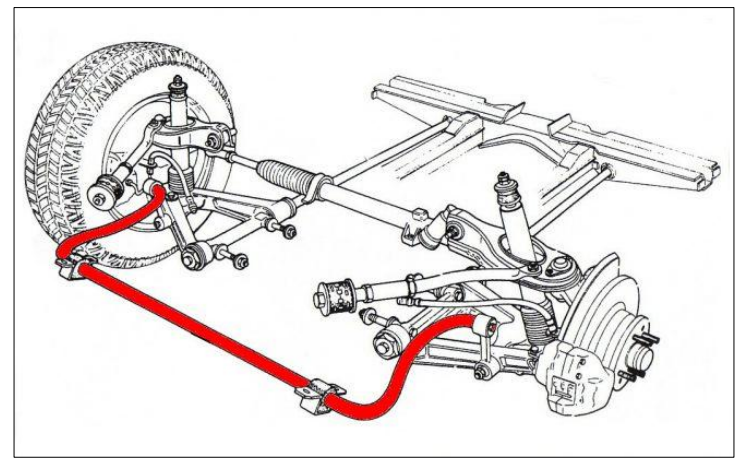

Fig 1. Anti Roll Bar 
International Journal of Applied Engineering Research ISSN 0973-4562 Volume 15, Number 9 (2020) pp. 906-910

(C) Research India Publications. https://dx.doi.org/10.37622/IJAER/15.9.2020.906-910

\section{DESIGN AND SIMULATION OF ANTI ROLL BAR}

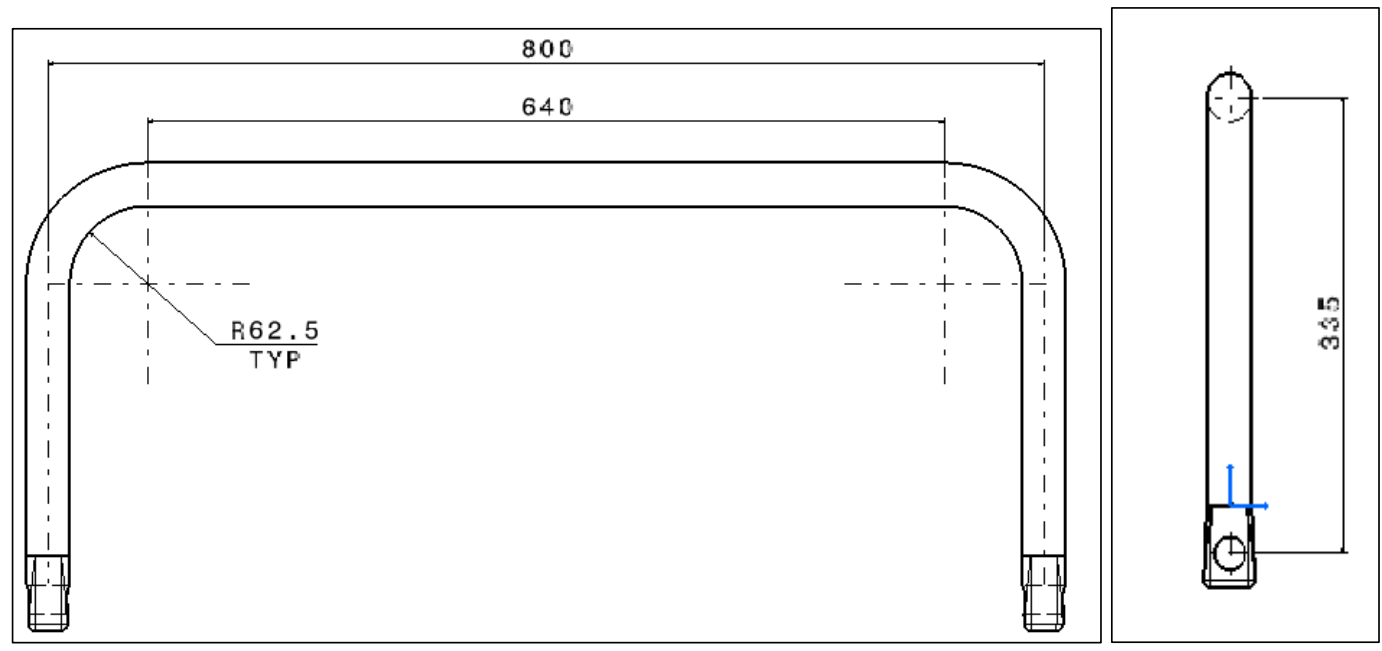

Fig 2a. 2D Model of Anti Roll Bar.

Design of Anti Roll Bar is based on survey. 3D modeling and 2D drawing is done on CATIA V5..

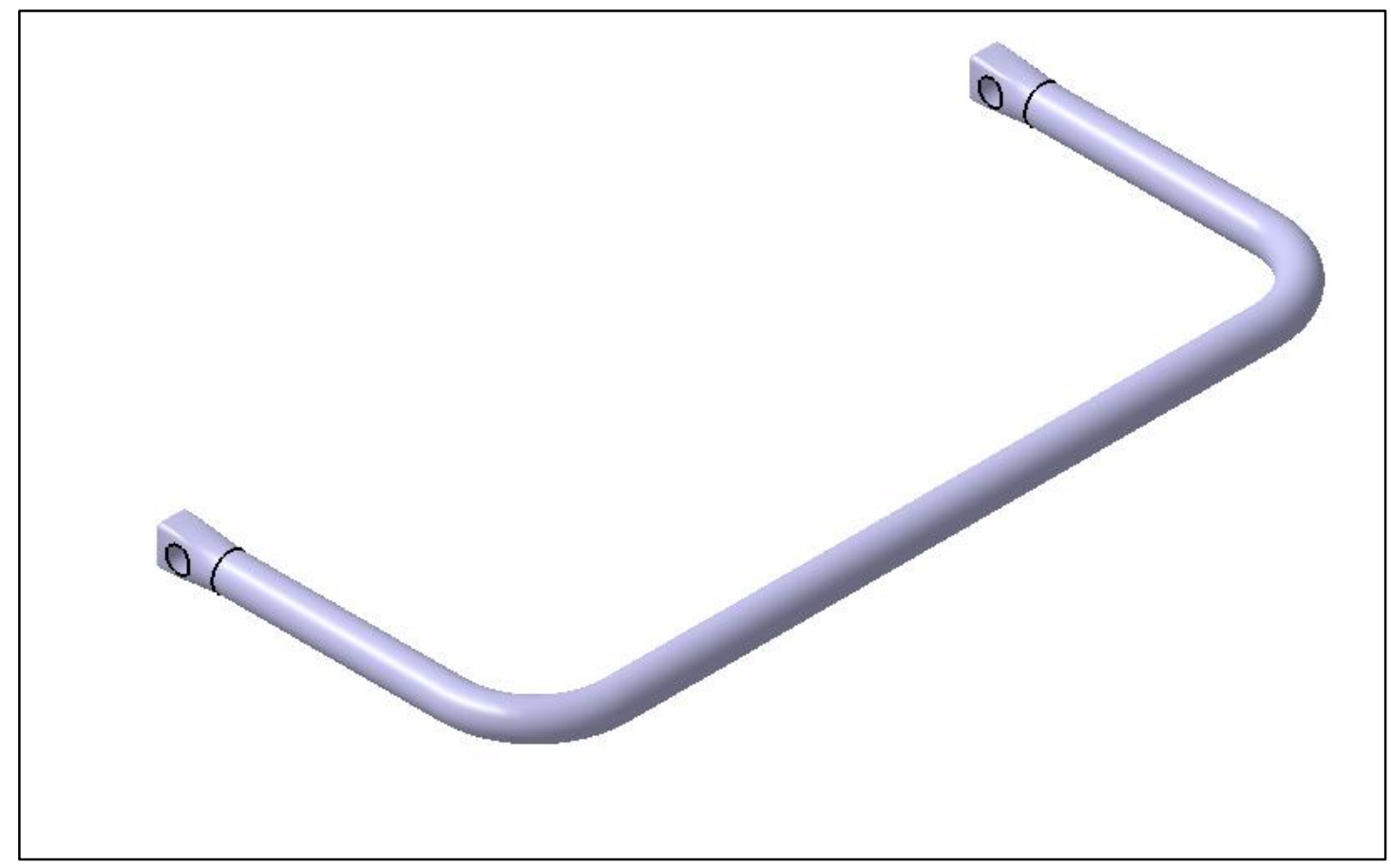

Fig 2b. CAD Model of Anti Roll Bar.

Below are the parameters of Anti Roll Bar.

Length Of Anti Roll Bar $=800 \mathrm{~mm}$

Arm Length $=350 \mathrm{~mm}$

Diameter of Anti Roll Bar $=35 \mathrm{~mm}$

Material $=$ En8 
4. ANALYSIS OF THE EFFECT OF CAMPING DISTANCE ON ROLL STIFFNESS AND STRESS.

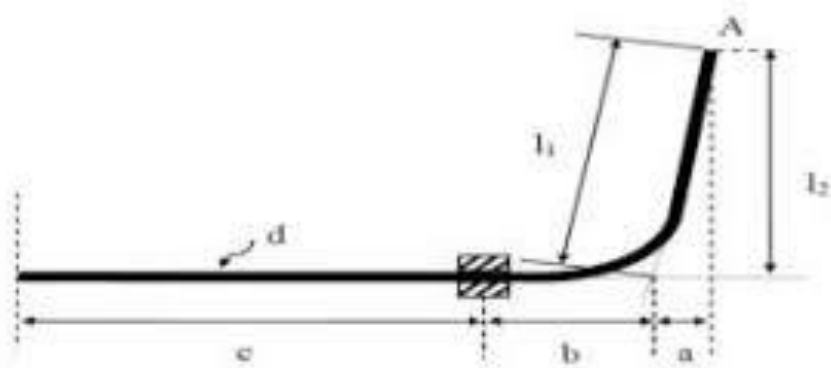

Fig 3. Anti Roll Bar Line Diagram

Anti Roll bar line diagram describes the terminology and which is referred from the Spring design Manual.

${ }^{[5]}$ Roll Stiffness of Anti Roll Bar $=\frac{\left(3 \mathrm{E} \mathrm{I} L^{2}\right)}{2\left[l_{1}^{3}-a^{3}+\frac{L}{2}(a+b)^{2}+4 l_{2}^{2}(b+c)\right]}$ N.mm / rad

$\mathrm{E}=210000 \mathrm{M} \mathrm{Pa}$ (Young's Modulus).

$\mathrm{I}=\frac{\pi d^{4}}{64} \mathrm{~mm}^{4}$ (Moment of Inertia).

$\mathrm{L}=$ Length of Anti roll Bar.

$\mathrm{a}=$ offset distance.

$\mathrm{b}=$ clamp to mounting distance.

$\mathrm{c}=$ center to clamp distance.

$1_{1}=l_{2}=$ Arm length.

\subsection{Consideration for Stress Analysis}

1. Deflection of $100 \mathrm{~mm}$ at both eye end in opposite direction.

2. Steel bush is used for clamping.

3. Connection between clamp and Anti roll bar is contact.

\section{Case I: Roll stiffness}

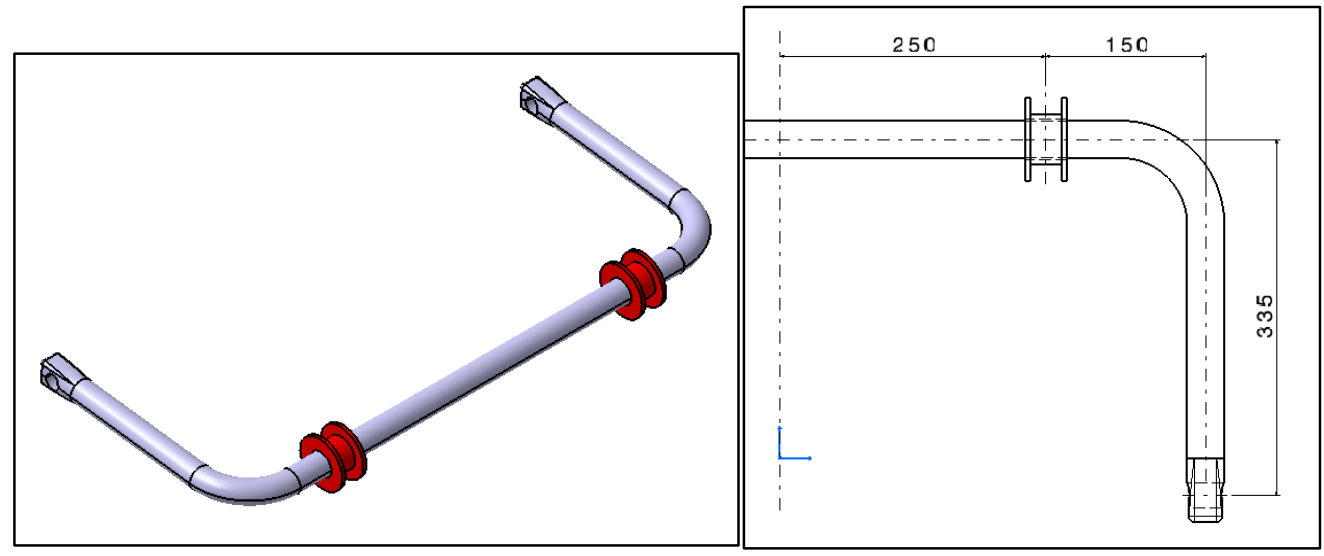

Fig 4. Clamping Case I.

In case I clamping distance is $250 \mathrm{~mm}$ from center of Anti Roll Bar.

Roll Stiffness of Anti Roll Bar $=\frac{\left(3 \mathrm{E} I L^{2}\right)}{2\left[l_{1}^{3}-a^{3}+\frac{L}{2}(a+b)^{2}+4 l_{2}^{2}(b+c)\right]}$
N.mm / rad

Clamping distance $=250 \mathrm{~mm}$

Roll Stiffness of Anti Roll Bar $=1562.673$ Nm/degree 


\section{Stress Analysis}

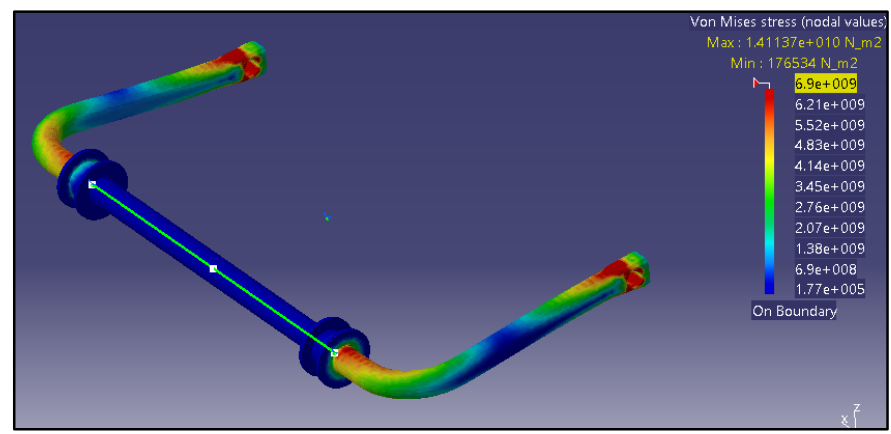

Fig 5. Case I Stress Analysis

After applying material the connection of clamp and anti roll bar is given and $100 \mathrm{~mm}$ of deflection is applied at the eye end of Anti Roll Bar but as earlier mentioned it is applied in opposite direction means at right eye deflection is applied at upward direction and at left eye the deflection applied at downward direction.

Max Stress $=1.41137 \mathrm{e}^{10} \mathrm{Nm}^{2}$

\section{Case II: Roll Stiffness}

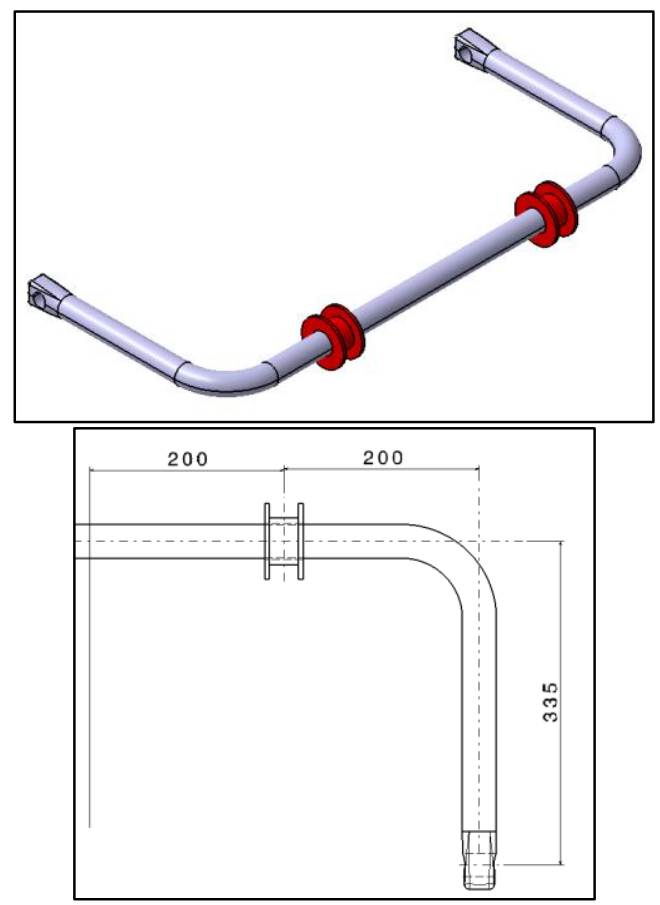

Fig 6. Clamping Case II.

In case II clamping distance is $200 \mathrm{~mm}$ from center of Anti Roll Bar.

Roll Stiffness of Anti Roll Bar $=\frac{\left(3 E \mathrm{E} L L^{2}\right)}{2\left[l_{1}^{3}-a^{3}+\frac{L}{2}(a+b)^{2}+4 l_{2}^{2}(b+c)\right]}$ N.mm / rad

Clamping distance $=200 \mathrm{~mm}$

Roll Stiffness of Anti Roll Bar $=1515.844$ Nm/degree

\section{Stress Analysis}

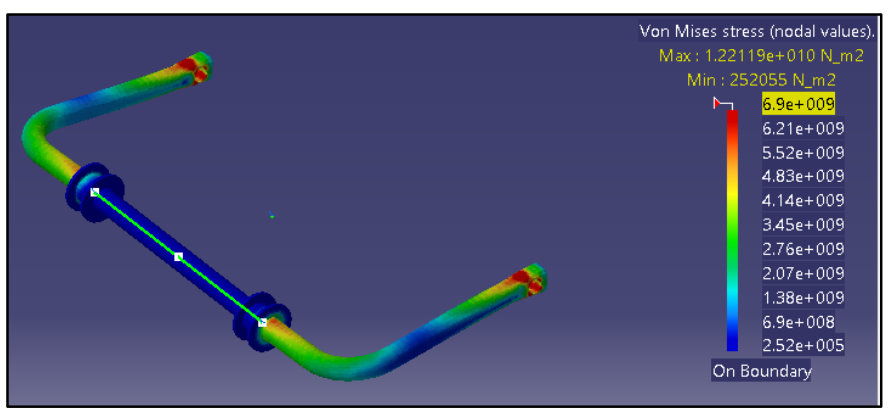

Fig 7. Clamping Case II.

Same steps for Case II are followed

Max Stress $=1.22119 \mathrm{e}^{10} \mathrm{Nm}^{2}$

\section{Case III: Roll Stiffness}

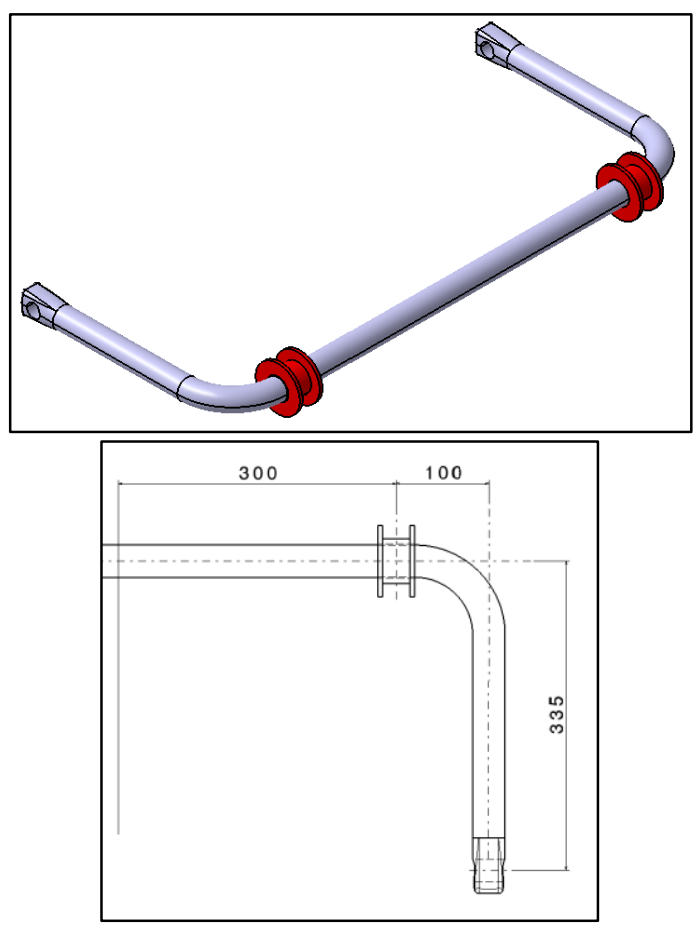

Fig 8. Clamping Case III.

In case III clamping distance is $300 \mathrm{~mm}$ from center of Anti Roll Bar.

Roll Stiffness of Anti Roll Bar $=\frac{\left(3 \mathrm{E} I L^{2}\right)}{2\left[l_{1}^{3}-a^{3}+\frac{L}{2}(a+b)^{2}+4 l_{2}^{2}(b+c)\right]}$ N.mm / rad

Clamping distance $=300 \mathrm{~mm}$

Roll Stiffness of Anti Roll Bar = 1598.094 Nm/degree 


\section{Stress Analysis}

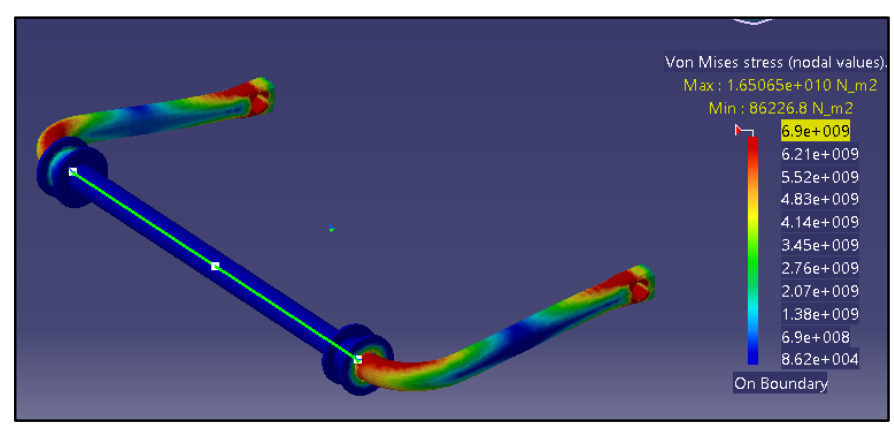

Fig 9. Clamping Case III.

Same Steps for Case III are followed.

Max Stress $=1.65065 \mathrm{e}^{10} \mathrm{Nm}^{2}$

\section{RESULT AND DISCUSSION.}

After designing Anti Roll Bar, the rolling stiffness was calculated analytically by considering a clamping distance of $250 \mathrm{~mm}$. Also the stress analysis was done by CATIA V5 by keeping contact connection of clamping bush (steel bush) and applying 100mm of deflection at eye end of Anti Roll Bar but in opposite direction to achieve the twisting scenario. Two more cases were also analysed were clamping distance was changed and following are the results obtained:

- Case I is considered as reference for comparing the roll stiffness and stress analysis of Case II and Case III.

- For Case II the clamping distance is reduced by $50 \mathrm{~mm}$ with respect to Case I and it has been found that rolling stiffness is reduced by approximately $3 \%$, whereas stress is reduced by approximately $13.5 \%$.

- For Case III the clamping distance is increased by 50 $\mathrm{mm}$ with respect to Case I and it has been found that rolling stiffness is increased by approximately $2.25 \%$, whereas stress is increased by approximately $17 \%$.

\section{CONCLUSION}

From the analysis it is concluded that roll stiffness of Anti roll Bar is increased by increasing its clamping distance, but stress induced in it is also increased. Percentage of increased roll stiffness is near about $2.25 \%$, whereas around $17 \%$ of stress is increased. Thus following are the important conclusions.

- Change in clamping distance changes the roll stiffness of Anti Roll Bar.

- Increase in clamping distance increases roll stiffness of Anti roll Bar.

- Stress induced in Anti roll bar increases as clamping distance is increased.

\section{REFERENCE}

[1]. Mohammad Durali and Ali Reza Kassaiezadeh, -Design and Software Base Modeling of Anti- Roll Systemll SAE PP - 2002-01- 2217.

[2]. Mr. Pravin Bharane, and Mr. Kshitijit Tanpure Optimization of Anti-Roll bar using Ansys Parametric Design Language (APDL), IJERGS Volume 2, Issue 5, August-September, 2014 ISSN 2091-2730.

[3] J. E. Shigley, C.R. Mischke, -Mechanical Engineering Designll 5th Ed. McGraw-Hill, pp. 282-289, 1989

[4] D.J Bickerstaff - The Handling Properties of Light Trucks, SAE - 1976

[5] SAE Spring Committee, - Spring Design Manualll, 2nd Ed., SAE, pp. 215-267, 1996

[6] Zhong-Xing Li1, Rong-Zhou Xu - Roll Stiffness Optimization for Anti-roll Bar in Interconnected Air Suspension, JASE, Vol. 19, No. 3, pp. 293_302 (2016)

[7] N. Zulkarnain, H. Zamzuri - Ride and Handling analysis for an active anti-roll bar: case study on composite nonlinear control strategy, IJAME Volume 10, pp. 2122-2143, July-December 2014. 